\title{
A INTERNET DAS COISAS E PROCESSO DE DESENVOLVIMENTO DE PRODUTOS: ESTUDO DE UM CASO
}

João Catarino (joao.catarino@esce.ips.pt) - Escola Superior de Ciências Empresariais, Instituto Politécnico de Setúbal, Portugal.

\section{RESUMO}

A Internet das Coisas (IoT - Internet of Things) fará com que os produtos continuem a evoluir mesmo depois de entrarem na fase de pós-desenvolvimento. A relação das firmas com os seus produtos se está transformando de forma a se tornar contínua e sem um fim bem definido. Os produtos ao se tornarem mais inteligentes e conectados irão obrigar a alterar a forma como as firmas fazem a gestão do processo de desenvolvimento de produtos.

Neste artigo iremos analisar as implicações da IoT, nos modelos de referência para a gestão do processo de desenvolvimento de produto, através de um estudo de um caso, de um fornecedor multinacional de soluções eletrônicas infoentretenimento para a indústria automotiva. Os nossos principais objetivos são: a) analisar o modelo de gestão do processo de desenvolvimento de produtos existente na empresa e explorar as implicações da IoT na forma como este está definido; b) analisar as implicações para a engenharia e para a manufatura da informação gerada pelos novos produtos inteligentes.

Veremos em particular, como a IoT irá obrigar à transformação e ainda maior integração entre as diversas áreas funcionais relacionadas com o desenvolvimento de produto, ao surgimento de novas áreas funcionais inexistentes na firma, bem como a uma nova forma de conceber e produzir os novos produtos. Veremos também na nossa análise que as implicações da IoT no desenvolvimento de produtos não está limitada às fronteiras da organização e se estendem a toda a cadeia de suprimentos.

Palavras chave: Internet das Coisas, Gestão de Processos de Desenvolvimento de Produto, Engenharia, Manufatura.

Área: Gestão do Processo de Desenvolvimento de Produtos 


\section{INTRODUÇÃO}

A necessidade de desenvolver novos produtos, inovadores e orientados para o mercado tem sido objeto de muito estudo na comunidade acadêmica e profissional. Em vários setores econômicos, a dinâmica da concorrência tem sido marcada por esse fato. Setores como a indústria automotiva, a de software ou a eletrônica de consumo são alguns exemplos de onde o desenvolvimento destes novos produtos é crítico para o sucesso empresarial.

Neste contexto, a gestão de desenvolvimento de novos produtos é vital para a competitividade e sobrevivência das organizações (VIEIRA ET AL., 2016). Por um lado, o processo de desenvolvimento de produtos (PDP) determina entre $70 \%$ a $90 \%$ do custo final do produto, além de determinar o seu desempenho em qualidade e diferenciação. Por outro lado, a vantagem competitiva de uma empresa está diretamente ligada à sua capacidade de introduzir no mercado novos produtos com conteúdo tecnológico e características que atendam às exigências dos consumidores (IBID).

A frase 'Internet das Coisas' (IoT - Internet of Things) resume uma nova geração de produtos conectados à internet e dotados de inteligência, no sentido em que possuem sensores, atuadores, microprocessadores, capacidade de armazenamento de dados e um software aplicacional embebido no produto e/ou disponibilizado através da internet. Estes produtos são capazes de interagir com o usuário, com outros produtos e são geradores de quantidades enormes de informação. $\mathrm{O}$ fato de os produtos estarem conectados à internet tem um impacto na forma como o valor é produzido. $\mathrm{O}$ foco deixa de estar no produto industrial, mas sim nos serviços disponibilizados ao usuário pela conexão do produto à internet (FERBER, 2013). Isto fará com que as empresas tradicionais de manufatura necessitem de desenvolver novos produtos, inteligentes e conectados. Desenvolver produtos no âmbito da IoT irá alterar as funções tradicionais das unidades funcionais associadas a esta atividade - engenharia (no sentido da atividade de pesquisa \& desenvolvimento), marketing, logística, manufatura, recursos humanos, suprimentos e finanças (PORTER; HEPPELMANN, 2015). Este fato irá trazer desafios acrescidos às organizações (FERBER, 2013) e obrigará a alterar a forma como o PDP está definido.

O objetivo deste artigo é analisar as implicações da IoT, nos modelos de referência para a gestão do processo de desenvolvimento de produto, através de um estudo de um caso, de um fornecedor multinacional de soluções eletrônicas de infoentretenimento para a indústria automotiva. Os nossos principais objetivos são: analisar o modelo de gestão do processo de desenvolvimento de produtos existente na empresa; explorar as implicações da IoT na forma como este está definido e analisar as implicações para a engenharia e a manufatura da informação gerada pelos novos produtos inteligentes.

Segundo (VOSS ET AL., 2002) a metodologia de estudo de caso é um dos mais poderosos métodos em gestão de operações. Segundo os mesmos autores, o fato de não estar restringida aos modelos rígidos dos questionários, pode levar a novas abordagens criativas e ao desenvolvimento de novas teorias. A nossa principal motivação é a análise aprofundada da situação concreta, procurando descobrir o que nela há de mais essencial e característico e propor uma nova metodologia também aplicada ao caso concreto, mas que possa ser generalizada, em futuros trabalhos, para modelos mais conceptuais e teóricos.

O presente trabalho está estruturado da seguinte forma: A seção 2 apresenta a empresa, analisa o atual PDP e faz as necessárias considerações bibliográficas que servem de suporte à análise. A seção 3 explora as aplicações de IoT na indústria eletrônica de infoentretenimento 
para o setor automotivo. A seção 4 analisa as implicações da IoT na forma como o PDP está definido na empresa estudada e apresenta as considerações finais do artigo.

\section{ESTUDO DE CASO}

\subsection{A empresa}

A empresa analisada é um fornecedor multinacional de soluções eletrônicas de infoentretenimento para a indústria automotiva. A empresa tem uma presença global, com 22 fábricas em vários continentes (América, Europa e Ásia). Dispõe também de centros de pesquisa e desenvolvimento em países como os EUA, México, França, Alemanha, Portugal, Bulgária, Índia e China.

Os seus clientes são os fabricantes de veículos automóveis, que incorporam produtos de infoentretenimento nos seus veículos. No âmbito da cadeia de suprimentos, a empresa estudada é vulgarmente designada como um fornecedor tier 1; os fabricantes de veículos, neste contexto, são designados por OEMs (Original Equipment Manufacturers). Muitas vezes os outros níveis da cadeia de suprimentos são designados por tier x (sendo x o nível na cadeira de suprimentos em que se encontram).

Os produtos típicos de infoentretenimento, desenvolvidos e produzidos pela empresa são clusters de instrumento, displays e sistemas de áudio para veículos automóveis. Na figura 1 podemos visualizar produtos típicos, produzidos atualmente, pela indústria eletrônica de infoentretenimento.

Figura 1. Produtos típicos de infoentretenimento - esquerda: cluster de instrumentos; direita: display multifunções. Fonte: Cnet.com $(2012,2010)$
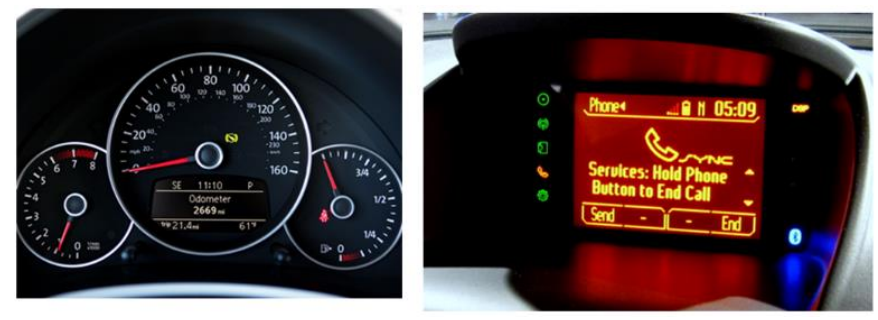

\subsection{O atual modelo de gestão de desenvolvimento de produto}

Nas últimas décadas, assistimos a um aumento da complexidade dos novos produtos lançados no mercado e ao consequente aumento da complexidade da função de desenvolvimento de produto. Múltiplos fatores contribuíram para esses fatos, nomeadamente o desenvolvimento de novas tecnologias, a necessidade de controlar custos de desenvolvimento e de produção e o aumento dos padrões de qualidade do produto desenvolvido. Se tornou necessário encontrar novas estratégias e metodologias que suprimam as lacunas da abordagem tradicional de desenvolvimento de produto. Esta abordagem era, em regra, baseada num modelo sequencial, no qual as atividades seguiam uma ordem lógica e quase sem interação entre as áreas funcionais da empresa (ROZENFELD ET AL., 2006). A partir do final da década de oitenta, surgem novas filosofias de gestão do PDP que visão coordenar de forma mais eficaz e eficiente todo o processo. Destacamos as abordagens de engenharia simultânea proposta por Carter e Baker (1992), de stage gates proposta por Cooper $(1993,1990)$ e o modelo unificado de Rozenfeld et al. (2006). Esta última abordagem integra as anteriores e reforça o papel 
estratégico do desenvolvimento de produto, a necessidade de integração funcional e a simultaneidade de atividades e informações.

A indústria automotiva é hoje um dos principais setores econômicos a nível mundial. Um veículo automóvel é um produto de elevada complexidade e que integra centenas de outros produtos. A especificidade dos produtos que são integrados no veículo condiciona largamente o processo de desenvolvimento de produto (PDP) dos mesmos, bem como a organização da cadeia de valor. Os seguintes pontos ilustram algumas destas especificidades que são aplicáveis à empresa objeto de estudo:

- Ciclo de vida típico do produto: 15-20 anos;

- Conceito, especificações técnicas e funcionais: OEM;

- Pesquisa \& Desenvolvimento: tier 1, com duração típica de 2-3 anos;

- Produção: tier 1;

- Cadeia de suprimentos: fortemente integrada;

- Qualidade - Requisitos elevados. Gestão da qualidade feita com normas específicas da indústria (ISO/TS16949, VDA, AIAG);

- Processos de negócio - Colocação dos produtos no mercado, atendimento ao cliente, assistência técnica: OEM.

No caso de estudo que apresentamos, o PDP da empresa pode ser enquadrado no modelo unificado proposto por Rozenfeld et al. (2006). O modelo utiliza uma série de estágios de desenvolvimento e de atividades a executar em cada estágio. No final de cada estágio existe o denominado gate review (portão de controle) onde a qualidade do processo é controlada. $\mathrm{Na}$ figura 2 podemos observar uma visão geral do PDP atualmente existente na empresa. Este é composto por um conjunto de macro fases, havendo em cada uma destas um ou mais gates. Contrariamente ao proposto no modelo de referência original, onde em cada gate a equipe decide prosseguir, ou não, com o esforço de desenvolvimento de produto, neste caso o gate review sinaliza para a alta direção da empresa eventuais desvios ao processo e a necessidade de um maior acompanhamento do projeto ou alocação de recursos adicionais. A empresa tem os seus recursos organizados de forma matricial, estando o caráter estratégico e a integração funcional bastante marcado, na cultura da empresa. Não só a equipe de projeto é sempre composta por elementos das diversas áreas funcionais como as reuniões de decisão e acompanhamento fora dos gate reviews são muitas vezes compostas por gestores diversas áreas funcionais de nível intermediário.

Um aspeto caraterístico deste PDP é que em cada uma das macro fases a dimensão, composição e liderança da equipe são mudadas e adaptadas aos requisitos da mesma. Em cada macro fase, esta equipe é dirigida por um gestor de programa que coordena todas as atividades inerentes ao PDP bem como o relacionamento e comunicação com o cliente. As áreas funcionais que integram a mesma são tipicamente vendas, engenharia, manufatura, logística, suprimentos, finanças e qualidade. Em seguida descrevemos resumidamente cada uma das macro fases:

- Cotação ao cliente - Nesta macro fase é feito o planeamento estratégico de produtos (através do desenvolvimento de conceitos de design) e é desenvolvida a atividade comercial da empresa na procura de novos negócios. São também apresentadas propostas comerciais aos diversos clientes. A equipe de projeto é partilhada por vários projetos; 
- Modelo futuro - Após conquistar um novo projeto, se entra na macro fase de desenvolvimento de produto e de industrialização propriamente dita. É assignada uma equipe maioritariamente dedicada em exclusivo ao projeto, especialmente ao nível da engenharia, manufatura avançada (responsável pela industrialização e lançamento do produto) e suprimentos. Como podemos verificar pela figura existe um enfoque muito grande nesta macro fase e é onde existe o maior número de portões de controle do processo. Nesta macro fase são definidas as especificações técnicas e funcionais do produto, que se manterão inalteradas nas fases subsequentes. Ela se inicia com o planejamento do projeto e termina 90 dias após o lançamento do produto;

- Modelo corrente - O produto entra em produção, normalmente, em linhas de produção dedicadas que funcionam 24 horas por dia. A equipe de projeto é composta maioritariamente por elementos das áreas de manufatura, qualidade e logística. Uma vez que não se planejam alterações ao produto, não existem elementos engenharia dedicados em exclusividade ao produto. Os elementos de engenharia e de industrialização da macro fase anterior são assignados a outros projetos. Existe sim, um grupo de engenharia partilhado por vário projetos, que somente analisa e corrige problemas de qualidade encontrados no produto e implementa ações de redução de custos;

- Modelo passado - O produto é descontinuado, embora exista uma produção residual destinada a sobresselentes. É assignada uma outra equipe de projeto que se dedica exclusivamente a produtos em modelo passado. Existem linhas de manufatura dedicadas apenas a produção de produtos de modelo passado.

Figura 2. Visão geral do processo de desenvolvimento de produto.

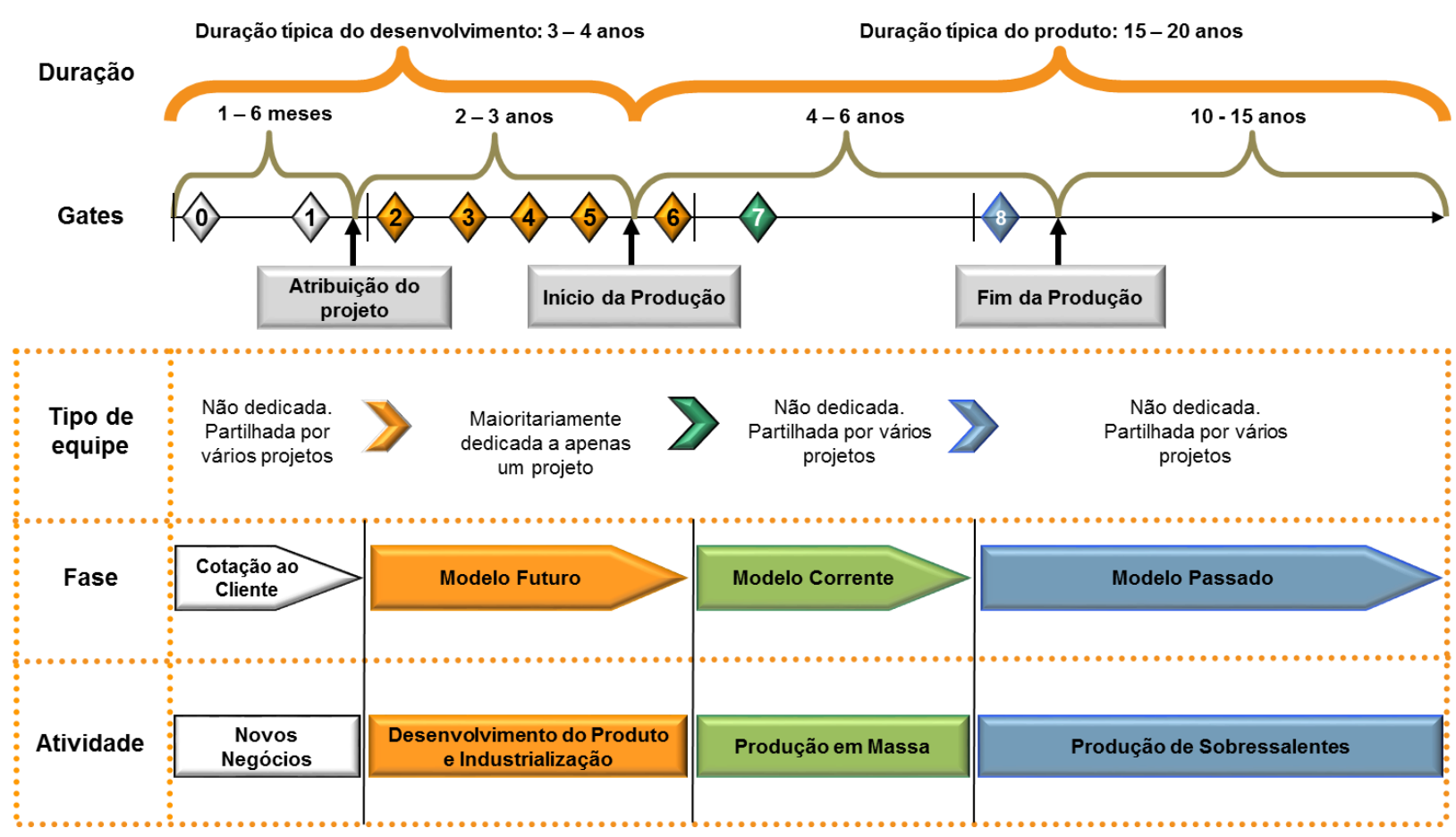

Para efeitos de análise posterior, em seguida descrevemos a dinâmica da equipe de projeto durante a macro fase de modelo futuro. De todas, esta é possivelmente a macro fase mais crítica, estando o projeto no seu auge de recursos, atividade e de portões de controle. A figura 3 pretende ilustrar, através de um diagrama, uma visão geral da forma com a interação da 
equipe ocorre entre a engenharia e a manufatura avançada, apresentado as principais atividades destas duas áreas funcionais e os principais componentes de projeto a serem produzidos (deliverables). Os deliverables do projeto são objeto de verificação nos gate reviews. Podemos também verificar a influência da abordagem da engenharia simultânea (com por exemplo o uso de técnicas de FMEA) e do uso de um sistema de gestão de qualidade típico da indústria automotiva (por exemplo processo de PPAP). O objetivo é procurar produtividade no desenvolvimento, garantir a qualidade dos produtos e a minimização do lead time do processo. Quando o design do produto e o processo de industrialização estão finalizados, o produto entra em produção em massa e a equipe de projeto é alterada, conforme descrito anteriormente. $\mathrm{O}$ foco passa a ser na produção e entrega do produto ao cliente.

Figura 3. Interação entre a equipe de engenharia e de manufatura avançada na macro fase de modelo futuro.

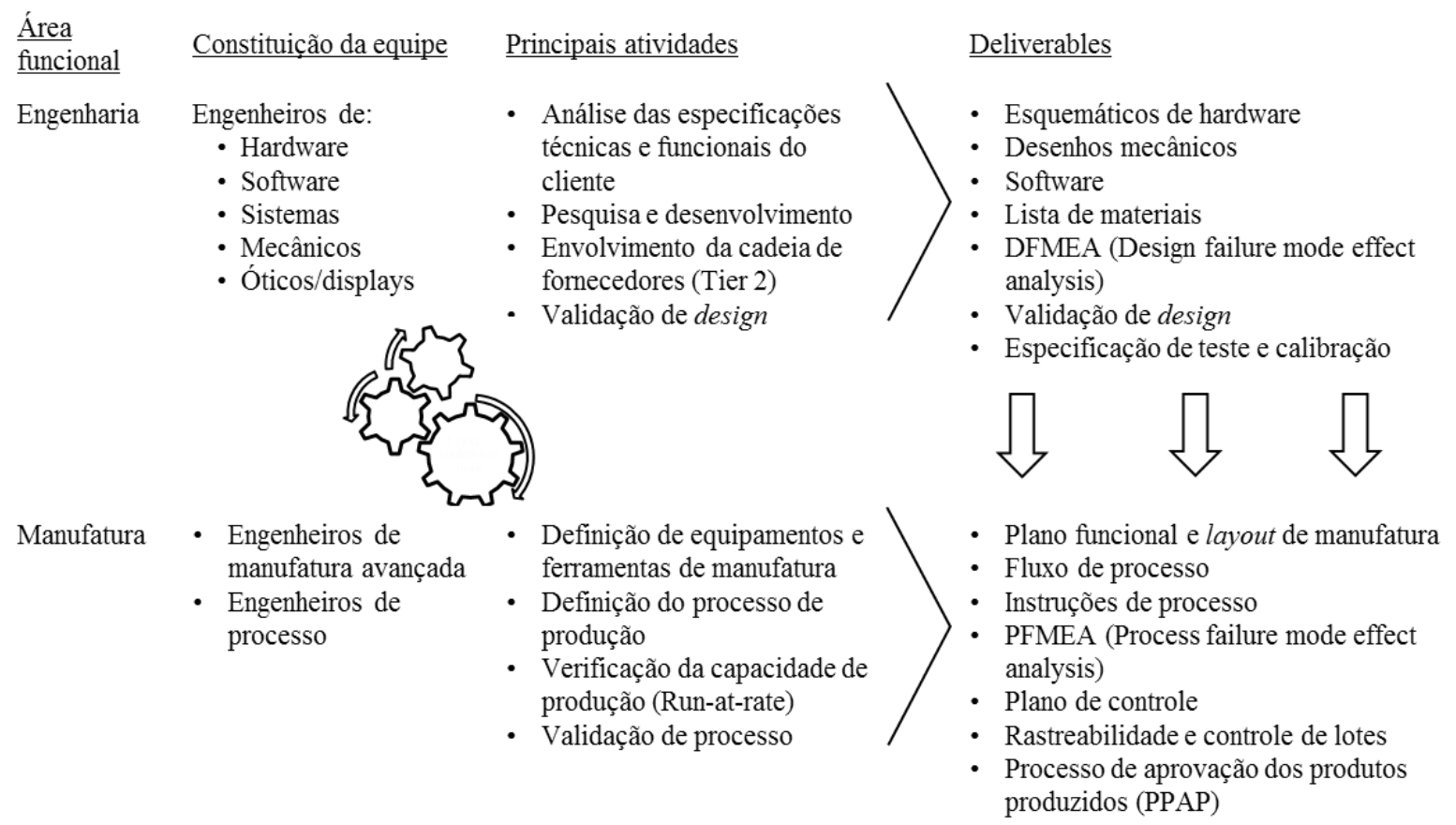

\section{A IOT NOS PRODUTOS DE INFOENTRETENIMENTO}

Atualmente se está vivendo uma mudança de paradigma tecnológico na indústria automotiva, com o surgimento do carro conectado e com funcionalidades de IoT. Este será um veículo inteligente capaz de se conectar à internet, de comunicar com outros dispositivos inteligentes e recolher dados em tempo real de múltiplas fontes. Estudos recentes estimam que em 2019, cerca de $20 \%$ de todos os veículos em circulação estejam conectados à internet (VODAFONE, 2016). Este fato irá desempenhar um papel fundamental na Internet das Coisas (COPPOLA; MORISIO, 2016).

A mudança de paradigma também se estende à indústria das soluções eletrônicas de infoentretenimento. Em futuras gerações, os novos produtos de infoentretenimento serão constituídos quase exclusivamente por hardware eletrônico, um display tátil e software aplicacional. Para além disso, os sistemas de infoentretenimento que irão integrar o carro conectado, deverão ser também dispositivos inteligentes, conectados, de interação com o usuário e agregadores de informação própria e de e outros dispositivos do ecossistema do carro conectado. Na figura 4 podemos visualizar um diagrama exemplificativo do ecossistema 
do carro conectado (esquerda), bem como a arquitetura dos novos produto de infoentretenimento e da sua infraestrutura tecnológica de suporte (direita). Como podemos observar na figura, estes novos produtos vão obrigar a que as empresas disponham de uma nova infraestrutura tecnológica de suporte ao seu funcionamento (MANYIKA ET AL., 2015; PORTER; HEPPELMANN, 2014). Esta infraestrutura permitirá um conjunto acrescido de novas funcionalidades, que como já foi referido terá um impacto significativo na forma como o valor é produzido.

O produto será divido em duas componentes: a componente física composta por hardware, software aplicacional embebido e um sistema de comunicações para suportar a conectividade do produto. Haverá uma outra componente do produto, que denominamos de produto cloud, composta por um conjunto de aplicações de software alojadas em servidores existentes na internet. Estas aplicações alojadas na internet serão compostas tipicamente por uma base de dados que regista os dados gerados pelo produto, uma componente de sofware aplicacional que disponibiliza funcionalidades do produto não embebidas no mesmo e uma plataforma de análise de dados, que fará a análise e fusão de dados através de algoritmos de inteligência artificial. O produto cloud disporá também de interface a outras ferramentas de negócio da empresa como é o caso do ERP (enterprise resource planning) corporativo, do CRM (customer relatioship management) e outros processos de negócio, como por exemplo plataformas de suporte ao PDP (IBID).

De acordo com Porter e Heppelmann (2015), esta arquitetura e sua infraestrutura de suporte permitiram novas funcionalidades do produto. Segundo os autores surgirão novas funcionalidades de monitorização, controle, otimização. Será expetável que, com recurso a algoritmos de inteligência artificial, os produtos aprendam a se adaptarem ao ambiente que os rodeia e às preferências do usuário, a efetuarem operação de autodiagnóstico e manutenção em si próprios, operando assim de forma autônoma (LEE; LEE, 2015).

Figura 4. Diagrama do carro conectado e do produto de infoentretenimento. Fonte: Adaptado de Coppola e Morisio (2016) (esquerda) e de Porter e Heppelmann (2014) (direita)

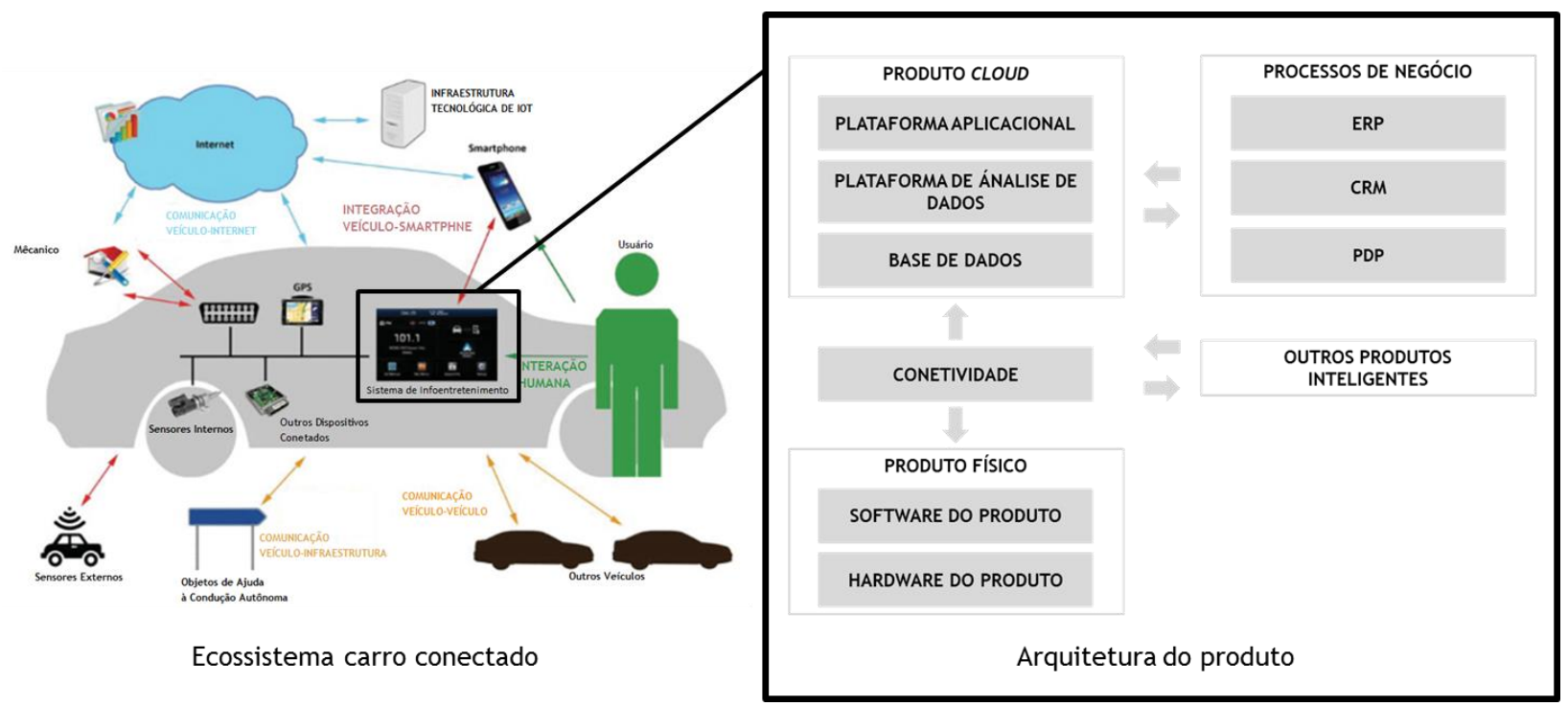

Como será expetável, esta nova arquitetura de produto com funcionalidades de IoT terá impacto nos processos de negócio das empresas. Para Ferber (2013) os processos de natureza estratégica, que se encontram no centro da organização, serão afetados por esta mudança. $\mathrm{Na}$ próxima seção analisaremos as implicações no PDP da empresa estudada. 


\section{IMPLICAÇÕES PARA O PDP DA EMPRESA ESTUDADA}

Como vimos na seção anterior, o desenvolvimento de software e os sistemas de informação passam a ter um papel central no desenvolvimento de novos produtos. Isto permitirá introduzir novas funcionalidades e aumentar a performance dos produtos durante todo o seu ciclo de vida. Assim, a relação das firmas com os seus produtos se irá transformar de forma a se tornar contínua e sem um fim bem definido. Esse fato obrigará a alterar a forma como estas fazem a gestão do PDP e dos restantes processos de negócio. Em seguida destacamos os principais aspetos que irão afetar o PDP da empresa estudada face a esta nova realidade.

Do ponto de vista de recursos humanos, serão necessários recursos em novas áreas de especialização, algumas delas inexistentes na empresa, como é o caso do desenvolvimento de algoritmos de inteligência artificial e de análise de dados. Haverá também um incremento dos recursos associados ao desenvolvimento de software e de sistemas de informação. Estes novos recursos integrarão a equipe de desenvolvimento de produto alterando significativamente a composição e âmbito da equipe de engenharia. Passará também a existir atividades de engenharia que serão transversais a todos os produtos da organização, como é o caso do armazenamento, segurança e análise de dados, o desenvolvimento de módulos de software e aplicações comuns a vários produtos. Estas atividades serão efetuadas de forma continuada e deverão ser asseguradas por equipes dedicadas.

A possibilidade de introduzir novas funcionalidades e aumentar a performance dos produtos durante todo o seu ciclo de vida fará com que os produtos continuem a evoluir mesmo depois de entrarem na fase de pós-desenvolvimento. A conetividade permitirá o desenvolvimento e atualização de software durante todo o ciclo de vida do produto. Ao mesmo tempo se poderá fazer uso dos dados de utilização e diagnóstico, disponibilizados pelos produtos, para proceder a alterações de engenharia com vista à redução de custos, aumento de qualidade e performance do produto. Em seguida apresentamos alguns exemplos de como isso poderá acontecer:

a) Poderão ser eliminadas funcionalidades não utilizadas, baixando desta forma o custo do produto sem qualquer impacto no usuário final;

b) A análise de falhas e identificação da sua causa raiz passara a ser realizada em tempo real. Poderá também ser feita a fusão com os dados de rastreabilidade provenientes da manufatura, com alterações feitas ao processo produtivo e a integração destes dados com outros níveis da cadeia de suprimentos, assegurando uma análise mais eficiente;

c) Poderão ser desenvolvidos novos componentes para evitar falhas específicas resultantes de design ou do processo de manufatura. Deverão ser criadas novas abordagens para a criação e uso de FMEAs, com base nos dados de diagnóstico do produto em utilização no terreno;

d) O uso de técnicas como o DfSS (design for six sigma) conjugado os dados de diagnóstico e ambiente que os rodeia poderá levar ao relaxamento da tolerância de alguns componentes, baixando desta forma o custo do produto.

Contrariamente ao que acontecia na empresa, a equipe de engenharia deverá continuar o desenvolvimento do produto após o início da produção. Para garantir a qualidade do processo será necessário fazer um controlo periódico das atividades através da introdução de gate reviews adicionais. A quantidade de gate reviews não deverá ser fixa, mas apenas dependente das evoluções do produto. Verificamos também a necessidade de uma maior integração entre as áreas funcionais e que se deverá também estender a outros níveis da cadeia de suprimento, no caso de outros fornecedores de tecnologias que integram o produto. 
Finalmente destacamos que a infraestrutura de sistemas de informação de suporte à IoT leva, de forma natural, a empresa a uma abordagem de gestão do ciclo de vida dos produtos. A fácil integração de dados e atividades com o ERP da empresa, nomeadamente ao nível da manufatura e finanças, e o fato de haver atividades de engenharia partilhadas por vários produtos, possibilitarão o gerenciamento integrado multiprojetos, permitindo maximizar, por exemplo, o fluxo de novos produtos e a otimização dos investimentos em tecnologia tal como referido por Rozenfeld et al. (2006).

Na figura 5 apresentamos uma proposta de reformulação da visão geral do PDP da empresa, adaptada à nova realidade trazida pela IoT e que resume o que foi discutido ao longo dos últimos parágrafos. Naturalmente que se trata de uma visão macro do PDP e haveria muito mais para discutir e analisar. No nosso entender deve também ser dado um enfase especial na criação de processos de gestão de conhecimento dentro da organização, não só porque a gestão do conhecimento é necessária para manter uma vantagem competitiva sustentada, no atual contexto econômico global (SANTORO ET AL., 2017), mas também porque há uma relação multidimensional entre esta e com a capacidade de inovar (IBID).

Figura 5. Proposta para novo processo de desenvolvimento de produtos IoT.

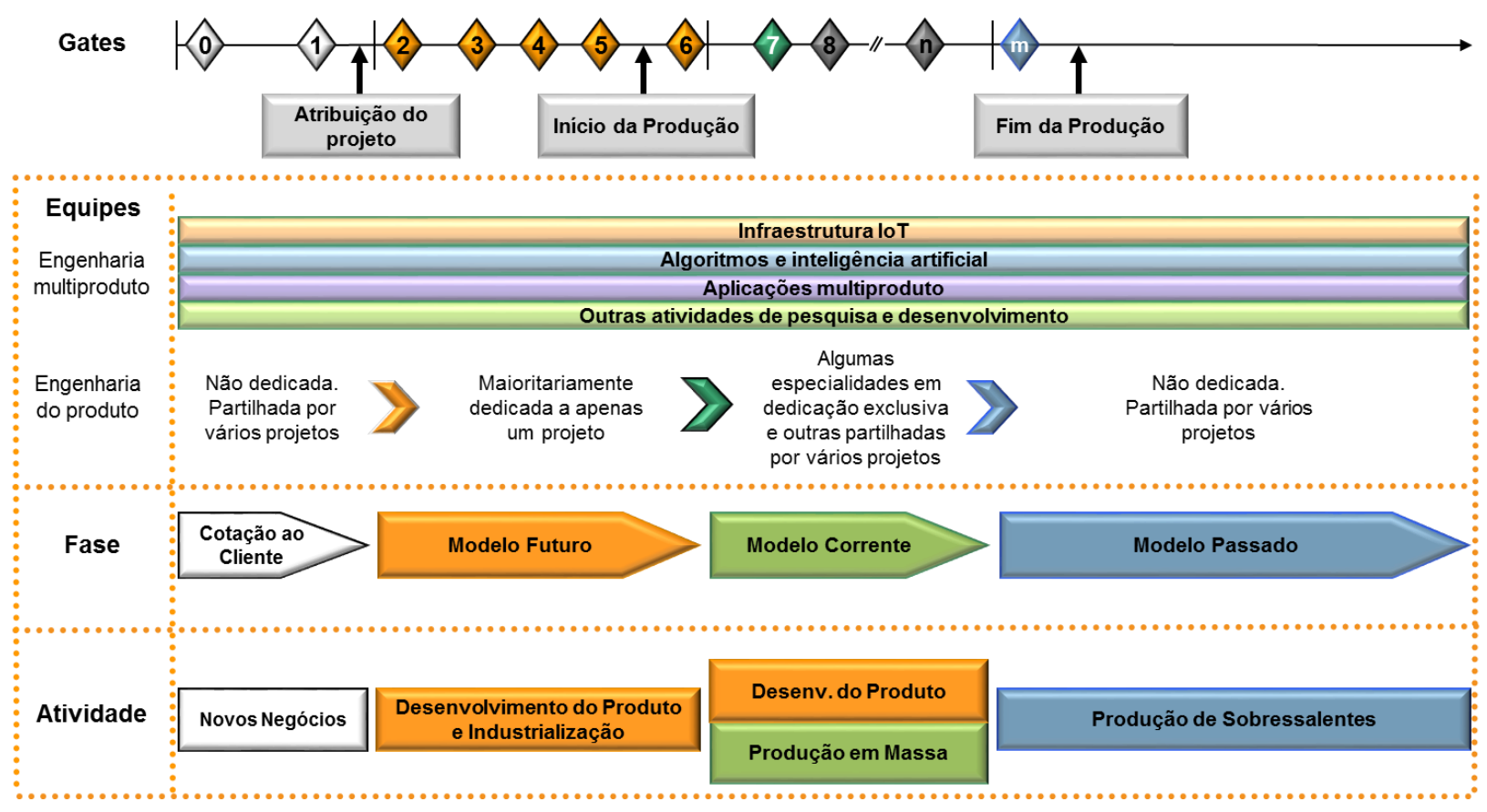

A Internet das Coisas trará consigo uma mudança profunda na forma de operar das empresas de fabricação. Tanto quanto é do nosso conhecimento, o nosso trabalho é o primeiro que analisa o impacto da IoT no PDP de uma empresa real e que faz propostas concretas de alteração do mesmo. Esperamos ter contribuído para uma melhor compreensão do impacto da IoT no PDP estudado e eventualmente que a nossa análise possa ser utilizada o desenvolvimento do PDP de outras empresas.

Como sugestão para estudos futuros, propomos o desenvolvimento de novas linhas de pesquisa com o objetivo de propor modelos de referência para a gestão do PDP de empresas de fabricação de produtos com funcionalidades de IoT, de âmbito mais conceitual e de aplicabilidade mais genérica. 


\section{REFERÊNCIAS}

CARTER, D.E.; BAKER, B.S. Ce Concurrent Engineering: The Product Development Environment for the 1990s. Addison-Wesley Pub, Reading, Mass., 1992.

CNET.COM. 2012 Volkswagen Beetle Turbo, 2012. URL

https://www.cnet.com/roadshow/pictures/2012-volkswagen-beetle-turbo-photos/11/ (acessado em 3.17.17).

CNET.COM. New Fiesta is no siesta: Ford's new runabout - Roadshow, 2010. URL

https://www.cnet.com/roadshow/news/new-fiesta-is-no-siesta-fords-new-runabout/ (acessado em 3.17.17).

COOPER, R.G. Winning at New Products: Accelerating the Process from Idea to Launch. Addison-Wesley, 1993.

COOPER, R.G. Stage-gate systems: A new tool for managing new products. Bus. Horiz. 33, 44-54, 1990.

COPPOLA, R.; MORISIO, M. Connected Car: Technologies, Issues, Future Trends. ACM Comput. Surv. CSUR 49, 46, 2016.

FERBER, S. How the Internet of Things Changes Everything, 2013. Harv. Bus. Rev. URL https://hbr.org/2013/05/how-the-internet-of-things-cha (acessado em 2.24.17).

LEE, I.; LEE, K. The Internet of Things (IoT): Applications, investments, and challenges for enterprises. Bus. Horiz. 58, 431-440, 2015.

MANYIKA, J.; CHUI, M.; BISSON, P.; WOETZEL, J.; DOBBS, R.; BUGHIN, J. Unlocking the potential of the Internet of Things. McKinsey Glob. Inst. McKinsey Co, 2015.

PORTER, M.E.; HEPPELMANN, J.E. How Smart, Connected Products Are Transforming Companies. Harv. Bus. Rev. 93(10), 96-114, 2015.

PORTER, M.E.; HEPPELMANN, J.E. How Smart, Connected Products Are Transforming Competition. Harv. Bus. Rev. 92(11), 64-88, 2014.

ROZENFELD, H.; FORCELLINI, F.A.; AMARAL, D.C. Gestão e Desenvolvimento de Produtos. Saraiva, São Paulo, 2006.

SANTORO, G.; VRONTIS, D.; THRASSOU, A.; DEZI, L.. The Internet of Things: Building a knowledge management system for open innovation and knowledge management capacity. Technol. Forecast. Soc. Change Article in Press, 2017. Doi:10.1016/j.techfore.2017.02.034

VIEIRA, A.V.; FONTES, A.R.M.; BORRÁS, M.Á.A.; FERRARINI, C.F. Modelo de referência para o desenvolvimento de produtos mecânicos. Prod. Produção 17, 62-79, 2016.

VODAFONE. Vodafone Automotive - Connected, Automated, Shared (White Paper). Vodafone, 2016.

VOSS, C.; TSIKRIKTSIS, N.; FROHLICH, M. Case research in operations management. Int. J. Oper. Prod. Manag. 22, 195-219, 2002. 